\title{
LÍNGUA E FASCISMO: CONFIGURAÇÕES DO OLHAR BARTHESIANO
}

\author{
Baktalaia de Lis Andrade LEAL*
}

- RESUMO: A partir da declaração de Barthes, afirmando que a língua é fascista, este artigo de opinião realiza uma relação entre os modelos político-ideológicos dos movimentos nazifascistas e as características do conceito de língua barthesiana. As análises caminham pelo campo da filosofia da linguagem e metaforizam os espaços do leitor, autor, texto e contexto de forma a trazer uma reflexão provocativa aos momentos históricos e quadros políticos dos últimos 80 anos. Para esse exame, leva-se em conta teóricos do campo da linguagem como Rodman e Fromklin (1993), Rajagopalan (2003), Fiorin (2008); na esfera da historiografia dialoga-se com Casara (2017), Woolf(1974), Trevor-Roper (1974), além de outros autores que circundam esta investigação de forma relevante. A medida em que se reflete sobre as razões dos pensamentos totalitaristas e verifica-se sua aproximação com a língua-autoritária vislumbrada por Barthes, pode-se mais facilmente compreender como as relações humanas precisam, muitas vezes, ser humanizadas. Como resultado deste estudo, pode-se considerar que os lugares discursivos são capazes de gerar aprisionamento ou liberdade, podem propor o fascismo ou a democracia pela literatura, e tais análises precisam ser contempladas.

- PALAVRAS-CHAVE: Fascismo. Nazifascismo. Língua. Barthes. Filosofia da Linguagem.

\section{Introdução}

A cadela do fascismo está sempre no cio

Bertold Brecht

Em seu livro Conversas com linguistas (2003), os autores Xavier e Cortez entrevistaram 18 renomados pesquisadores brasileiros da linguagem; dentre as várias perguntas feitas, destacamos uma que é fundamental: O que é língua? As respostas dos linguistas ganharam várias reações difusas, pois cada entrevistado apontou para uma ideia diferenciada do fenômeno Língua.

* Universidade do Estado da Bahia (UNEB), Brumado - BA - Brasil. baker.br@hotmail.com. ORCID: 0000-0001-75097263. 
Esse resultado não significa, de modo algum, que os respondentes não conhecem a matéria (afinal, são todos catedráticos), nem significa que a área dos estudos linguísticos se pulverizou e se perdeu numa incontida ramificação sem finalidade e funcionalidade. Apenas é preciso considerar prioritariamente que Língua é um elemento de estudo tão controverso e múltiplo quanto o é a Cultura ou a Psicologia, defini-lo é uma tarefa nada fácil e implica sobretudo em adotar uma compreensão teórico-filosófica à qual o conceito de língua se alinhe harmonicamente.

Assim, a língua pode ser descrita como algo comunicacional, expressivo, interativo, discriminador, codificável, decodificável, político, idiomático, algo anatômico, dentre muitos outros conceitos.

Roland Barthes faz uma afirmação sobre a língua que nos transporta para uma esfera entre o político e o estrutural, entre as relações humanas e o sistema morfossintático; obrigando-nos a entrar em uma filosofia da linguagem desconfortável. Barthes confiadamente diz: "Mas a língua, [...] não é nem reacionária, nem progressista; ela é simplesmente: fascista; pois o fascismo não é impedir de dizer, é obrigar a dizer" (BARTHES, 1992, p.14, grifo nosso).

Ao longo desta reflexão, irei defrontar as razões que associam a língua - como vista por Barthes - com os traços dos movimentos fascistas presentes nos últimos cem anos. As conexões serão mostradas com nitidez e se verá que o fascismo, como movimento de obrigação e obediência, ajusta-se perfeitamente ao julgamento realizado por esse pensador pós-estruturalista sobre a linguagem. Após esse trabalho de investigação bibliográfica e de opinião, apresentarei a proposta barthesiana de escape da prisão para a liberdade do ponto de vista literário. Portanto, objetiva-se: i) descrever um breve histórico do fenômeno fascista; ii) estabelecer comparações entre os traços do fenômeno do fascismo com a língua barthesiana, nesse investimento se manifesta a modalidade de artigo de opinião, posto que as comparações que se realizarão são de nossa inteira especulação teórica; iii) apresentar a ideia deste autor sobre liberdade na escritura.

Barthes declara que a língua é fascista, como se viu nessa apresentação, mas não explicitou com maiores detalhes e categorias as razões desta comparação, e nesse ponto esse artigo se propõe a opinar e fomentar com mais amplitude essa metáfora.

O gene do fascismo parecia (ou se mostrava) cadavérico ao final do Século XX, mas os ventos do início do novo milênio robustamente espalharam novas (velhas) sementes discursivas que rapidamente renovaram suas vozes por todos os lugares do mundo. Essa surpreendente ressurreição ideológica precisa ser observada com atenção e merece investigações mais criteriosas.

Nada parece mais propício que um especialista como Roland Barthes para perseguir e caçar um engano do passado adormecido. 


\section{O fascismo histórico}

Tal como o conceito de língua, fascismo (nazifascismo ou nazismo) ${ }^{1}$ é uma ideia vasta e de definição obscura. George Orwell (2017), em seu ensaio O que é o fascismo?, escreveu sobre a grande dificuldade de dar um significado ao termo, ao ponto de a máscara fascista parecer com uma batata-quente, ou seja, cada grupo político-filosófico quer lançar sobre o outro a faceta fascista. Dizer simplesmente a frase: Fora, fascistas!, não define consistentemente de quem se está falando. Isso pode ser verificado no trecho seguinte de Trevor-Roper (1974, p. 51-52):

O fascismo pode ser limitado no tempo e no espaço, pode ter tido um claro princípio e um claro fim na história pública; pode parecer facilmente definível. Mas esta unidade, esta definição fora-lhe artificialmente imposta. Por detrás de um só nome há cem formas distintas.

As múltiplas formas de sua manifestação trazem uma dificuldade de estabelecer um padrão de pronto. Um jornal tendencioso, um político arbitrário, uma lei abusiva ou um soldado autoritário, qualquer sinal do não diálogo pode ser um ato rotulado como fascista. Desta forma, um governo de esquerda, direita, anárquico ou monárquico pode ser assim classificado.

Classicamente, esse movimento ficou conhecido pelos governos de Hitler (na Alemanha) e de Mussolini (na Itália), e foram caracterizados por diversas particularidades como: perseguição e extermínio dos grupos de minoria (judeus, ciganos, negros, deficientes), nacionalismo exacerbado, poderio bélico para domínio mundial, dentre outras. É certo que as ações destes estadistas simbolizaram a ideia de fascismo para o mundo.

Mesmo sabendo das representações populares que se tem desses movimentos, é possível traçar características comuns e reconhecer que há padrões claramente detectáveis nos governos totalitaristas. Esses traços, que serão referenciados nas subseções seguintes, podem notadamente fazer emergir uma fronteira entre os governos dialógicos e os governos autoritários, e são esses traços que queremos elencar para estabelecer um paralelo com a língua conceituada no olhar barthesiano.

\section{A língua no pensamento de Barthes}

Conceituar língua é uma tarefa que depende de, além de formular uma explicação frasal, tomar uma posição filosófica e teórica frente ao fenômeno da linguagem. Barthes assim o faz, concebe a língua como estrutura dominante do sujeito, assim, não é o ser

Fascismo, Nazifascismo, Nazismo: trataremos todos como um só conceito, embora possam ser encontradas ligeiras diferenças desses termos nos escritos de historiadores e sociólogos. Popularmente aceita-se que o fascismo é a face italiana do nazismo alemão. 
que domina a linguagem, mas o indivíduo é por ela assujeitado. Num texto qualquer, a voz que fala não é a do autor ou a do escritor, mas a da própria linguagem.

De modo que, embora Barthes lute em sua teoria para se desvencilhar em direção ao caminho pós-estrutural, seu conceito sobre língua é essencialmente saussuriano. Língua é a estrutura que se coloca no centro de toda construção comunicativa e à ela se assujeitam o autor e o leitor. Nessa progressão Barthes propõe a morte do autor e promete o nascimento do leitor, esse último encontra-se numa sobrevida que é asfixiada pelo aspecto soberano da estrutura da língua. Comparar a língua ao fascismo é a simbologia ideal para o conceito de língua construído.

Em Barthes, a língua ganha uma dominância sobre os outros elementos pertencentes à interação, e esse controle da linguagem enquanto estrutura condena e assujeita o corpo que fala a expressar-se unicamente pela língua que conhece. Ou seja, se alguém desejar dizer algo, está limitado a dizê-lo nos parâmetros que a sua língua o permita que o diga, nada poderá ser dito fora da língua. A linguagem é o compósito dos limites possíveis da significação. Daí explica-se o texto recortado, a língua "não é nem reacionária, nem progressista; ela é simplesmente: fascista; pois o fascismo não é impedir de dizer, é obrigar a dizer" (BARTHES, 1992, p. 14). O autor rejeita a ligação da língua com imagens da política bipolarizada: reacionária versus progressista. Isso pode ser verificado ao analisar historicamente os movimentos políticos do Século XX, quando houve a opção pelo fascismo existente entre guerras:

Nem uma sociedade socialista, nem uma sociedade capitalista regenerada de seus males, nada disso viera a findar o conflito mundial. Por que nesse caso não acreditar na possibilidade de uma "terceira solução"? Nem capitalista nem bolchevista? É aí que se situa o nacional-socialismo, não apenas o alemão, mas aquele que integra todos os movimentos fascistas.

(CALAZANS FALCON, 1974, p. 28-29).

Para Barthes, a língua está numa outra modulação de matiz analítica. Não se trata de direita versus esquerda, capitalismo versus comunismo. Não se trata de progressos ou retrocessos linguísticos, se trata de pertencimento do sujeito a uma estrutura que não o liberta, que o impede até de se calar, que coage a dizer a saudação obrigatória: Heil, Hitler! Assim, seria inteiramente inadequado etiquetar a língua sem observar seus tentáculos estruturais inesquiváveis.

\section{Crise Social}

O fascismo, enquanto movimento político-ideológico, surge sempre quando uma sociedade está em crise e desacreditada dos modelos econômicos. A crise social é o cenário ideal para a emersão da terceira solução, mesmo se o mundo já estiver vigorosamente diversificado em opiniões. 
No Século XX, foi preciso que dois polos estivessem entrincheirados frente-afrente para que uma terceira margem surgisse no espaço/tempo preciso e se vestisse com fardas de solução, como se verifica no trecho: “[...] existem características comuns ao aparecimento histórico dos movimentos fascistas, [...] conjuntura em crise, quer no nível econômico, quer no nível político, quer no nível ideológico”. (CALAZANS FALCON, 1974, p. 18, grifo nosso).

Mesmo quando não há somente dois lados, é preciso que se faça parecer que existe uma guerra entre dois opostos oportunistas, para que a saída advenha de uma nova forma de ver o mundo, uma renovação em meio à crise. A crise pode ser, como observou Calazans Falcon, de qualquer natureza - econômica, política, ideológica -, a Itália e a Alemanha passavam por convulsões a beira de colapsos, ambiente propício para que colocassem a fé nos partidos nazifascistas.

A língua também passa por momentos de mudanças e metamorfoses, embora as mudanças linguísticas sejam uma naturalidade na história das linguagens, há sempre os agentes de controle que militam para salvaguardar a língua da interação humana das modificações geradas pela própria fala.

A língua, monitorada pelos joysticks dos gramáticos controladores, reage muito fortemente contra as mudanças e os puristas sempre enxergam qualquer mudança como novas conjunturas de crise, fomentando um terreno produtivo para a ação da polícia gramatical:

Parece ter existido, em todos os períodos do passado, tal como agora, uma nítida apreensão no espírito de muitas pessoas honradas quanto ao estado de quase colapso iminente da língua [...] quanto a necessidade de constantemente se desenvolverem esforços árduos que a salvem da destruição. (RODMAN; FROMKLIN, 1993, p. 15).

A língua, de fato, nunca está em crise, ela segue seu curso natural de mudanças pelos usos e trabalho dos seus falantes, mas alguns querem fazer parecer que ela está perdida e deficiente. Como apontou Mattos e Silva: “A língua portuguesa na sua variedade brasileira não está em crise, nem à deriva, como querem muitos, mas segue a sua deriva, ou as suas derivas [...] para caracterizar o curso das mudanças históricas da língua" (MATTOS E SILVA, 2004, p. 72).

As línguas naturais então sempre mudando por meio de diversos processos comprovados. Alguns fenômenos linguísticos próprios de todas as línguas operam essas modificações (CARVALHO, 2009), como: os neologismos, os estrangeirismos, os afixos, a gramaticalização, as monotongações, as derivações impróprias, os contatos entre línguas diferentes, as variações e muitos outros fatores (embora não consensuais) provocam uma história linguística muito acidentada. Contudo nenhuma desses elementos modificadores da língua estabelecem uma crise perniciosa, são meios naturais para o percurso histórico de qualquer idioma, mas os puristas da língua apontam as mudanças 
como algo maléfico e patológico de uma possível crise. Para esses conspiradores, é preciso reconhecer uma anomalia e fazê-la crida.

Sem a crise, não há fascismo. Em meio à crise, entre a variação e a mudança... escolhe-se a tradição.

\section{Segregacionismo}

Na representação do nazifascismo emergente no Século XX, eclode o discurso em defesa de uma suposta raça ariana e única, misticamente investida de direitos soberanos sobre as outras raças. Claramente o racismo não é um fenômeno que nasceu dentro do fascismo, pois o racismo é uma mentalidade antiquíssima e de dimensão mundial, mas as investidas mortais de Hitler e Mussolini contra os judeus, os negros, os ciganos e qualquer outra etnia não caucasiana foram justificadas pelo sistema de ideias e objetivos de uma raça pura:

[...] Temos de lutar pela existência e a proliferação de nossa raça, das pessoas, pela subsistência de seus filhos e manutenção de nossas ações contra a mistura racial, pela liberdade e independência da pátria, para que nosso povo possa ser estimulado a cumprir a missão que lhe foi atribuída pelo Criador. (HITLER, 1976 [1925], p. 202).

Existe um tipo de devoção na doutrina hitleriana que ultrapassa o limiar do político e do social, a obstinação pela raça imaculada parece fazer valer qualquer pena, de tal modo que a busca pelo purismo racial é um tipo de ministério sacerdotal, uma missão outorgada pelo próprio Criador. Uma parte do mundo viu essa concepção como um pensamento doentio, mas outra parte encontrou sua identificação nos discursos segregacionista, racial e fascista.

A existência de grupos neonazistas em todo o mundo atualmente corrobora que esse discurso ainda coopta a muitos. Para Arendt o racismo nazista foi bem mais forte que racismo francês, que até então era o mais consolidado: “[...] até a época em que $o s$ nazistas [...] admitiram com franqueza o seu desprezo por todos os povos, [...] o racismo francês foi o mais consistente". (ARENDT, 2000 [1949], p. 195-204, grifo nosso).

Semelhante ao cesarismo hitleriano, a língua é, por natureza, segregacionista. O léxico é carregado de verbetes separatistas e difamadores. A exemplo da língua portuguesa, na qual há muitas palavras e expressões linguísticas fortemente marcadas pela sua etimologia difamatória, tem-se termos como: mulato de mula, denegrir de negro, doméstica de domesticar, aluno de ser sem luz, judiar de judeu e inúmeros outros termos bastante usados em contextos segregacionistas claros ou disfarçados. Fiorin, refletindo sobre o politicamente correto na linguagem, ao mesmo tempo em que se preocupa com o funcionamento da língua na liberdade de expressão, também aponta 
para a necessidade de verificar os aspectos linguísticos que fomentam o preconceito e a discriminação:

[...] não basta mudar a linguagem para que a discriminação deixe de existir. Entretanto, como a conotação negativa é uma questão de grau, não é irrelevante deixar de usar os termos mais fortemente identificados com atitudes racistas, machistas etc. (FIORIN, 2008, p.1).

Seria preciso observar no que realmente a língua insiste em macular o outro para que se deixe de usar o termo que é ofensivo e isso não se dá em todos os casos de etimologia injuriosa, em alguns casos, o significado original já não indexa mais o preconceito.

Não obstante, a língua é historicamente separatista na sua constituição interna e frequentemente se torna preciso atualizar o uso politicamente correto do idioma, pois a estrutura realiza registros de novas e constantes formas de racismo, segregação e discriminação.

\section{Nacionalismo}

Uma das características mais fortes dos movimentos fascistas é o ufanismo extravagante. Hitler alarmava seus slogans mais atrativos para seduzir a massa alemã instigando a ideia de que a supremacia da nação não deve conhecer limites: "Eu tinha tantas vezes cantado Deutschland über alles ('Alemanha acima de tudo')" (HITLER, 1976 [1925], p. 154). Esse era o fundamento ideológico do Führer, a nação estava acima de tudo, inclusive das outras nações. Com o fenômeno da memória discursiva, esses discursos perpassam por gerações e asseguram sua longa existência em outros lugares e em outros momentos, colocando o mesmo enunciado em novas enunciações, a mesma voz em novas bocas:

[...] discursos que originam um certo número de novos atos, de palavras que os retomam, os transformam ou falam deles, enfim, os discursos que indefinidamente, para além de sua formação, são ditos, permanecem ditos e estão ainda por dizer. (FOUCAULT, 2014 [1971], p. 24).

Não somente o traço nacionalista, mas toda a mentalidade fascista se recompõe em novos atos e novas palavras, com merecidos destaques irônicos para os adjetivos.

Sobre a história dos governos totalitaristas, Woolf comenta que: "O fascismo foi preponderantemente nacionalista, e firmemente arraigado ao desenvolvimento histórico de cada país". (WOOLF, 1974, p. 39, grifo nosso). Afinal, não parece restar dúvidas de que o nacionalismo foi (é) uma condição sine qua non para a subsistência dos governos totalitários. 
Outro episódio confirmador: sob a égide do lema Trabalho, família e Pátria, Phillippe Pétain, Chefe de Estado francês (1940-1944), colaborou com o nazismo alemão na implantação das ideais de Hitler quando este invadiu a França (MANDEL, 1995). O slogan é mais um indicativo do nacionalismo presente no projeto de germanizar o mundo.

O patriotismo também é vivo na realidade da língua, pois o fenômeno da linguagem circunda e exclui em uma atitude protecionista, conquanto a língua recorta o que é de seu pertencimento e exclui o que pertence a outro sistema. Não se trata de estrangeirismo, pois como vimos, a língua abraça e reveste as palavras e expressões estrangeiras sobretudo os anglicismos são bem aceitos no Brasil -, trata-se de uma identidade que (mesmo que seja folclórica) estabelece o nacionalismo linguístico: "A língua é muito mais que um simples código ou um instrumento de comunicação. Ela é, antes de qualquer outra coisa, uma das principais marcas da identidade de uma nação, um povo. Ela é uma bandeira política.” (RAJAGOPALAN, 2003, p. 93).

Longe das discussões sobre a existência ou não de uma unidade linguística nacional, há razões para concordar com Rajagopalan sobre as identidades de nacionalidade construídas pelos limites da linguagem. Há, inegavelmente, línguas que gozam de privilégios sobre outras, e isso decorre de motivos que vão além das fronteiras da linguagem, são causas sociais, políticas e econômicas que tornam o inglês o idioma de prestígio no mundo; porém, a língua é o receptáculo dessa carga de estigmatização internacional.

Essa faceta não é nova, desde tempos imemoriais, as línguas são parâmetros para legitimar ou descredibilizar povos e nações antigas: "É, mais uma vez, a atitude que levou os gregos a chamar de bárbaros todos aqueles que não falavam grego e que consiste em desclassificar o outro, desclassificando sua língua". (ILARI; BASSO, 2006, p. 195). Portanto, a língua é nacionalmente cismática já há muito tempo antes do fascismo se estabelecer enquanto movimento político-ideológico.

\section{Autoritarismo}

Em um Estado totalitário, o autoritarismo é aplaudido e celebrado como um arquétipo necessário para o desenvolvimento nacional, o senso democrático é relegado apenas ao nível sensorial e nos limiares do sermão. Na prática, a coisa participativa inexiste. Deve-se acreditar na figura de um salvador, um messias líder idealizador da terceira solução ou ainda da solução final. A esse indivíduo ofertam-se a faculdade e a crença de resolução, crê-se no autoritarismo quando a pseudodemocracia falha.

Arendt ${ }^{2}$ considera que o autoritarismo é uma forma de ação do governo totalitarista, essa ação acopla-se ao sentimento de violência e gera sua escalada:

Arendt faz diferença entre tiranias, governo autoritário e totalitarismo, porém não é relevante explorar sua tese neste trabalho. Apenas é preciso compreender que o autoritarismo é uma ferramenta para impor as razões totalitárias. 
Por detrás da identificação liberal do totalitarismo com o autoritarismo, e da concomitante inclinação a ver tendências "totalitárias" em toda limitação autoritária, jaz uma confusão mais antiga de autoridade com tirania e de poder legítimo com violência. (ARENDT, 2016 [1954], p. 134, grifo nosso).

O autoritarismo restringe liberdade, por isso é um braço forte dos governos totalitaristas, mas esse controle é estabelecido entre confusões de licitudes, ou seja, tirania e violência vão encontrando espaço sem ninguém saber ao certo quem ou o quê legitima suas práticas intransigentes.

Barthes aponta para o controle da linguagem sobre o sujeito, o centramento da estrutura regula autoritariamente a existência das relações linguageiras: a língua na perspectiva barthesiana é um lugar de controle pleno já que dentro dos limites da língua não há espaço para o sujeito, o leitor ou o autor, pois a linguagem é quem fala, a língua é totalitária:

Na língua, portanto, servidão e poder se confundem inelutavelmente. Se chamamos de liberdade não só a potência de subtrair-se ao poder, mas também e sobretudo a de não submeter ninguém, não pode haver liberdade senão fora da linguagem. Infelizmente, a linguagem humana é sem exterior: é um lugar fechado. Só se pode sair dela pelo preço do impossível. (BARTHES, 1992, p. 15-16).

Autor e leitor revezam-se de lugares e posições estando ambos cativos no autoritarismo da língua, de onde não se pode escapar porque não há nada fora dela. $\mathrm{O}$ descentramento do sujeito é significativo, enquanto a estrutura detém o centro, a autoridade.

\section{Religiosidade}

Finalmente, a devoção religiosa é um traço peculiar e indispensavelmente usual dos governos autocráticos, mesmo quando de esquerda, quando o Estado se torna a religião das massas. Esse é um dos pontos cruciais (dentre outros também importantes) para assegurar que Hitler não executava um governo socialista de nenhuma vertente embora seu partido fosse chamado Partido Nacional-Socialista - posto que a tradição das doutrinas socialistas se distancia das causas religiosas. O nazifascismo têm predominância de traços fortemente cristianizados em seus princípios, possui coligações político-religiosas muito bem aliançadas e sustenta discursos altamente espiritualizados, como se verifica nos trechos seguintes: 
[...] tanto na Itália quanto na Alemanha, o partido fascista chegou ao poder por uma porta similar, porta que foi aberta pela Igreja Católica. Naturalmente não foi só a Igreja Católica a responsável. A Igreja, nisso, atuou como representante da sociedade conservadora. (TREVORROPER, 1974, p. 61).

E ainda: "Por isso, acredito agora que ajo de acordo com as prescrições do Criador Onipotente. Lutando contra o judaísmo, estou realizando a obra de Deus" (HITLER, 1976 [1925], p. 64, grifo nosso). A fé torna-se um alicerce para a consolidação das forças políticas que pretendem chegar ao poder e estabelecer um Estado totalitário. Nas campanhas políticas - e vale ressaltar que o líder mais emblemático do nazismo (Hitler) também foi eleito pelo voto -, o manejo retórico das falas que veiculam os símbolos cristãos é usado para garantir a empatia da sociedade conservadora que facilmente se identifica com esses valores. Não se deve pensar, quando Trevor-Roper aponta sociedade conservadora, que está se referindo a parcela de idosos da sociedade, a juventude elitizada das sociedades alemã e italiana foram recrutadas ideologicamente com muita força pelos partidos. O nazifascismo usou (usa) o ímpeto social de ver sua religião ser bem representada pelos governantes.

Em análise paralela, a língua também se conecta ao indivíduo pela interface da religiosidade, ou melhor, a religiosidade está imbricada à língua de forma tênue, mas significante. A religião escondida na linguagem manifesta-se: pelas interjeições, Nossa!, Credo!; nas palavras-tabu, Desgraçado!, Maldito!, pelas expressões que desfazem maldição Deus é mais!, Tá amarrado!; na obrigação mística de desejar saúde a quem espirra, e na cortesia de responder amém a quem disse saúde; através dos nomes próprios que declaram bênção, Benedito, Gabriel ${ }^{3}$; em superstições no prepor um tratamento ao nome do morto, Finado João era um homem bom; no medo de pronunciar nomes de doenças mortais, João está com 'c'; no modo quase silencioso de falar câncer, AIDS ou palavras de morte, doenças ou maldições:

Em algumas culturas, ao ouvirem certas palavras, as pessoas têm de anular o seu efeito "tocando em madeira". [...] uma criança judia não pode herdar o nome de outra pessoa ainda viva e em certas culturas é proibido anunciar o nome de alguém que já morreu. [...] falam-nos da importância da linguagem e das suas propriedades miraculosas que os homens lhe atribuem. (RODMAN; FROMKLIN, 1993, p. 15).

A língua é repleta de guarnições místicas que já estão em pleno funcionamento antes de nascermos, seus recursos religiosos interpelam-nos e não se pode duvidar deles, não se pode desobedecer às indexações canonizadas da linguagem. Vê-se a

\footnotetext{
O nome próprio Benedito advém do Latim Benedictus que significa bendito, abençoado. Gabriel tem origem no hebraico e significa homem de Deus.
} 
facilidade com que a estrutura linguística nos sequestram para a sua congregação de significados invisíveis e inexplicáveis, pois não há explicação lógica para obedecermos aos misticismos linguísticos, mesmo assim, normalmente, não ousamos subvertê-los.

\section{Liberdade?}

Diante de tantos elementos escravagistas e antidemocráticos insistentemente históricos, podemos pensar que não há, de fato, um espaço de liberdade entre a linguagem, o pensamento e as relações humanas. $\mathrm{O}$ fascismo poderia ser aniquilado no mundo real? A língua pode deixar de ser eternamente fascista?

Não se pode perder de vista o fato de que sempre estamos diante de manifestações de vontade de poder, ou seja, o eu está sempre no desejo de dominar o tu quando a relação não é dialógica (no sentido humanizador do dialogismo bakhtiniano) e harmônica. Em Foucault (2014 [1971], p. 33) encontramos a exposição desse conflito quando o discurso de verdade se estabelece como égide de poder e domínio sobre o outro. A linguagem como ferramenta de domínio também é notada por Klemperer (2009, p. 55): “O nazismo se embrenhou na carne e no sangue das massas por meio de palavras, expressões e frases que foram impostas pela repetição, milhares de vezes, e foram aceitas inconscientemente e mecanicamente". O não diálogo é eminentemente compactuado com o aprendizado obrigatório de uma nova linguagem, a dos slogans, das frases prontas, dos cumprimentos e continências militares, das repetições.

O nazifascismo político filosófico não pode ser visto como um evento isolado ou um produto oriundo da mente de um psicopata fardado, Cytrynowicz (1995, p. 210) chama a atenção para isso:

Doença e vírus são imagens recorrentes para falar do fascismo, do nazismo, como se fosse um fenômeno passageiro, inesperado e, acima de tudo, um hospedeiro indesejado que teria deixado a história após uma breve e maligna estadia.

Um momento histórico passou, mas outros tantos podem eclodir com repetições de discursos e práticas que não necessariamente deixaram de existir, apenas estavam em estado de latência. Seria um pensamento igualmente inocente achar que todas as pessoas seguidoras dos agentes líderes dos governos totalitários agiram hipnotizados, pois como lembra Casara (2017, p. 60): “O Holocausto foi possível [...] pois contou com a ajuda de juristas e juízes". A clara realidade é que muitíssimos seres humanos quiseram (querem) que o nazifascismo existisse (exista).

O desejo de controle é um sumidouro glutão. É preciso ter em mente que a vontade de se encontrar superior ao outro é uma problemática que acha razoabilidade quando nossos desejos menos virtuosos se tornam realizáveis no arquétipo do egoísmo aplaudido. 
É preciso e possível humanizar a relação eu-tu, e não se pode garantir essa evolução senão pelo diálogo e pela participação popular. É preciso afrontar a tentação fascista em qualquer molde, e, sobretudo, não permitir a lesão dos direitos fundamentais pois: "cada vez que um direito fundamental é violado ou relativizado, caminha-se um passo rumo ao autoritarismo" (CASARA, 2017, p. 65).

Algo semelhante é a proposta de fuga do cárcere da língua. Barthes, sobre essa escravidão estrutural, escreve:

[...] só resta [a nós], por assim dizer, trapacear com a língua, trapacear a língua. Essa trapaça salutar, essa esquiva, esse logro magnífico que permite ouvir a língua fora do poder, no esplendor de uma revolução permanente da linguagem, eu a chamo, quanto a mim: literatura. (BARTHES, 1992, p. 16).

A literatura ou, ainda melhor, as manifestações das literaturas são as formas de escape dos tentáculos da língua. É isso que a linguagem literária faz, uma subversão linguística que se esquiva das estruturas da gramática e se torna plurimorfológica, assintática e ultrasemântica. Significando o incerto, multiplicando as possibilidades de reconhecimento do leitor (ou seja, do $t u$ ) como um autor legitimado. Frente a esse fascismo faminto manifestado na e pela língua, Barthes ilumina a porta da evasão: a literatura.

LEAL, B. Language and fascism: configurations of the barthesian look. Alfa, São Paulo, v.65, 2021.

- ABSTRACT: Based on Barthes' statement, stating that language is fascist, this opinion article establishes a relationship between the political-ideological models of the Nazifascist movements and the characteristics of the concept of the Barthesian language. The analyses go through the field of philosophy of language and metaphorize the spaces of the reader, author, text and context in order to bring a provocative reflection on the historical moments and political frameworks of the last 80 years. For this examination, theorists in the field of language are taken into account, such as Rodman \& Fromklin (1993), Rajagopalan (2003), Fiorin (2008); in the sphere of historiography, it dialogues with Casara (2017), Woolf(1974), Trevor-Roper (1974), in addition to other authors who surround this investigation in a relevant way. As we reflect on the reasons for totalitarian thoughts and see their approximation with the authoritarian language envisioned by Barthes, we can more easily understand how human relationships often need to be humanized. As a result of this study, it can be considered that discursive spaces are capable of generating imprisonment or freedom, they can propose fascism or democracy through literature, and such analyses need to be considered.

- KEYWORDS: Fascism. Nazifascism. Language. Barthes. Philosophy of Language. 


\section{REFERÊNCIAS}

ARENDT, H. Entre o Passado e o Futuro. Tradução de Mauro W. Barbosa de Almeida. São Paulo: Perspectiva, 2016. Original de 1954.

ARENDT, H. Origens do totalitarismo: anti-semitismo - imperialismo - totalitarismo. Tradução de Roberto Raposo. São Paulo: Companhia das Letras, 2000. Original de 1949.

BARTHES, R. Aula. Tradução de Leyla Perrone-Moisés. São Paulo: Cultrix, 1992.

CALAZANS FALCON, F. J. Origens históricas dos movimentos fascistas. In: RODRIGUES, A. E. M (org.). Fascismo. Rio de Janeiro: Eldorado, 1974. p. 23-46.

CARVALHO, N. Empréstimos linguísticos na língua portuguesa. São Paulo: Cortez, 2009.

CASARA, R. Estado pós-democrático: o neo-obscurantismo e gestão dos indesejáveis. Rio de Janeiro: Civilização Brasileira, 2017.

CYTRYNOWICZ, R. Loucura coletiva ou desvio da história: as dificuldades de interpretar o nazismo. In: COGGIOLA, O. (org.). Segunda Guerra Mundial: um balanço histórico. Tradução de P. B. Sória, S. F. Foá, H. Carneiro. São Paulo: Xamá: USP-FFLCH, 1995. p.207-219.

FIORIN, J. L. A linguagem politicamente correta. Revista Linguasagem, São Carlos, v.1, n.1, p. 1-5, ago 2008. Disponível em: http://www.linguasagem.ufscar.br/index.php/ linguasagem/article/download/532/296. Acesso: 10 abr. 2021.

FOUCAULT, M. A ordem do discurso. Tradução de Laura Fraga de Almeida Sampaio. 24. ed. São Paulo: Edições Loyola, 2014. Original de 1971.

HITLER, A. Minha Luta. Tradução de J. de Carvalho. Lisboa: Afrodite, 1976. Título original: Mein Kampf. Original de 1925.

ILARI, R.; BASSO, R. O português da gente: a língua que estudamos, a língua que falamos. São Paulo: Contexto, 2006.

KLEMPERER, V. LTI, A linguagem do terceiro Reich. Rio de Janeiro: Contraponto, 2009.

MADEL, E. Classes e personalidade na Segunda Guerra Mundial. In: COGGIOLA, O. (org.). Segunda Guerra Mundial: um balanço histórico. Tradução de P. B. Sória, S. F. Foá, H. Carneiro. São Paulo: Xamá: USP-FFLCH, 1995. p. 59-83.

MATTOS E SILVA, R. V. O português são dois: novas fronteiras, velhos problemas. São Paulo: Parábola Editorial, 2004.

ORWELL, G. O que é fascismo? In: AUGUSTO, S. (org.). O que é fascismo?: e outros ensaios. Tradução de Paulo Geiser. Rio de Janeiro: Companhia das Letras, 2017. 
RAJAGOPALAN, K. Por uma linguística crítica: linguagem, identidade e a questão ética. São Paulo: Parábola, 2003.

RODMAN, R.; FROMKLIN, V. Introdução à linguagem. Tradução de Isabel Casanova. Lisboa: Almedina, 1993.

TREVOR-ROPER, H. R. O fenômeno do fascismo. In: RODRIGUES, A. E. M (org.). Fascismo. Rio de Janeiro: Eldorado, 1974. p. 51-66.

WOOLF, S. J. Uma introdução. In: RODRIGUES, A. E. M (org.). Fascismo. Rio de Janeiro: Eldorado, 1974. p. 39-40.

Recebido em 16 de abril de 2019

Aprovado em 10 de julho de 2020 